\title{
Polymerization of Cholesteryl Methacrylate in the Mesophase
}

\author{
Hideo SAeki, ${ }^{*}$ Kazuyoshi Immura, and Masatami TAKedA \\ Department of Chemistry, Faculty of Science, Science University of Tokyo, \\ Kagurazaka, Shinjuku-ku, Tokyo, Japan.
}

(Received August 10, 1971)

\begin{abstract}
KEY WORDS Thermal Polymerization / Cholesteryl Methacrylate /
Mesophase / Isotropic Liquid / Mesomorphic Temperature /
\end{abstract}

Recent investigations on the polymerizations of cholesteryl acrylate ${ }^{1,2}$ and cholestanyl acrylate ${ }^{1}$ are of interest, since an effect can be expected on the monomeric order in the cholesteric mesophase on the nature of products. In these investigations, Toth and Tobolsky ${ }^{1}$ have reported that no thermotropic nature was observed for poly(cholesteryl acrylate), and de Visser, et al., ${ }^{2}$ have found no significant differences in conversion and in intrinsic viscosity between the polymers obtained in the mesophase and those in the isotropic liquid state.

In the course of our study on the thermal polymerization of cholesteryl methacrylate (CMA), however, it was found that the mesomorphic temperature lowers as the polymerization proceeds. In the present study, we wish to report this new interesting finding and the differences between the thermal polymerization of CMA in the mesophase and that in the isotropic liquid state.

CMA was prepared by refluxing cholesterol and methacryloyl chloride ${ }^{3}$ in a mixed solvent of ether and toluene. The reaction mixture was poured into methanol and the precipitated product was recovered. Repeated precipitation from the ether solution by dilution with methanol yielded a pure product (a needle- like crystal, $\mathrm{mp} 107.5^{\circ} \mathrm{C}$ ). The structure of product was identified by IR (JASCO, DS-403G) and NMR (Varian, A-60) measurements.

On heating the monomeric CMA in a glasscapillary tube, the solid sample melts to a trans-

\footnotetext{
* Present address: Central Research Laboratories, Mitsubishi Electric Corporation, Amagasaki, Japan.
}

parent isotropic liquid at $108-110^{\circ} \mathrm{C}$. Upon cooling the molten sample, a blue color appears at $108-104^{\circ} \mathrm{C}$ and remains until the temperature lowers to $102^{\circ} \mathrm{C}$, then the appearance of the sample becomes an opaque solid at $90-85^{\circ} \mathrm{C}$.

The thermal property of CMA was also measured with a differential scanning calorimeter (Perkin-Elmer, DSC-2) and was shown in Table I. The heating curve indicated a sharp endothermic peak at $109^{\circ} \mathrm{C}$ and successively a broad exothermic peak between $120-150^{\circ} \mathrm{C}$. The broad peak was caused by a thermal polymerization of CMA since it was not observed when hydroquinone (2\%) was added to the monomer. Upon cooling CMA from the temperature just above its melting point, two exothermic peaks were observed at 103 and $85^{\circ} \mathrm{C}$. The origin of a weak peak at $103^{\circ} \mathrm{C}$ was ascribed to a transition from the isotropic liquid to the cholesteric mesophase. The shape of the peak centered near $85^{\circ} \mathrm{C}$ depended on the thermal history of

Table I. Thermal properties of cholesteryl methacrylate

\begin{tabular}{|c|c|c|}
\hline & Heating & Cooling \\
\hline \multicolumn{3}{|c|}{$T_{\mathrm{m}}$ (crystal $\rightarrow$ isotropic liq) $\begin{array}{c}109^{\circ} \mathrm{C} \\
\text { (endothermic) }\end{array}$} \\
\hline$T_{1}($ isotropic liq $\rightarrow$ cholesteric $)$ & & $\begin{array}{l}103^{\circ} \mathrm{C} \\
\text { exothermic) }\end{array}$ \\
\hline$T_{\mathrm{c}}\left(\begin{array}{l}\text { cholesteric } \\
\text { mesophase }\end{array} \rightarrow\right.$ crystal $)$ & & $\begin{array}{l}85^{\circ} \mathrm{C} \\
\text { exothermic) }\end{array}$ \\
\hline Heat of fusion & \multicolumn{2}{|c|}{$11.3 \mathrm{cal} / \mathrm{g}$} \\
\hline 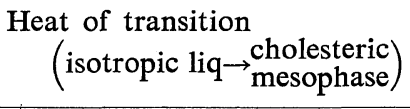 & \multicolumn{2}{|c|}{$0.3 \mathrm{cal} / \mathrm{g}$} \\
\hline
\end{tabular}


the sample. However, the temperature of the first appearance of the exothermic curve was reproducible at $88^{\circ} \mathrm{C}$.

The thermal polymerization of CMA in the mesophase was carried out as follows. By evaporating solvent from an ether solution of CMA, the powdery CMA was allowed to spread over the inner-wall of a glass ampule in a layer state. After melting the monomeric CMA at 110$115^{\circ} \mathrm{C}$, the ampule was immersed quickly in a glycerine bath where the temperature was kept constant at the mesomorphic temperature of $108^{\circ} \mathrm{C}$. Thermal bulk polymerization was then carried out. The ampule was kept oblique and rotated occasionally to avoid the flowing down of the sample layer attached to the inner-wall of the ampule.

The blue color, which was characteristic of the cholesteric mesophase of monomeric CMA, disappeared with the progress of the polymerization. When the temperature of the bath was lowered after standing the sample at $108^{\circ} \mathrm{C}$ for some time, the wall of ampule became luminous again in the blue color at a limited temperature region below $108^{\circ} \mathrm{C}$. The lowering of the mesomorphic temperature region is of considerable interest. A careful observation indicated that the temperature region of the color development found in the process of polymerization was proved to be reproducible for the sample once it has passed certain time of polymerization.

Table II. Conversions, molecular weights, and properties of poly (CMA)

\begin{tabular}{ccrrrr}
\hline $\begin{array}{c}\text { Sample } \\
\text { no. }\end{array}$ & $\begin{array}{c}\text { Polymeri- } \\
\text { zation } \\
\text { temp, } \\
{ }^{\circ} \mathrm{C}\end{array}$ & $\begin{array}{c}\text { Polymeri-Con- } \\
\text { zation } \\
\text { time, } \\
\text { min }\end{array}$ & $\begin{array}{c}\text { ver- } \\
\text { sion, } \\
\%\end{array}$ & $M_{n}{ }^{\mathrm{a}}$ & $\begin{array}{c}\text { Meso- } \\
\text { morphic } \\
\text { temp region, }\end{array}$ \\
\hline TBP-7 & 120 & 300 & 36 & 8800 & - \\
TBP-9 & 140 & 360 & 57 & 50000 & - \\
\hline TBP-B & 108 & 10 & 58 & 8000 & $109-104$ \\
TBP-C & 108 & 40 & 63 & 18500 & $108-99$ \\
TBP-D & 108 & 80 & 66 & 36000 & $98-90$ \\
TBP-E & 108 & 240 & 67 & 27000 & $63-13$ \\
TBP-F & 108 & 240 & 67 & 113000 & below 29 \\
\hline
\end{tabular}

a Number-average molecular weight of the polymers was obtained by using a VPO (Mechrolab, Model-302) in benzene solution at $37^{\circ} \mathrm{C}$, while, that above 50000 was obtained by a GPC (Waters, ANA-PREP) in THF solution.
These results are summarized in Table II. It is noted that the temperature region lowers as the polymerization proceeds and the molecular weight of the polymer increases. When the polymerization occurred to a considerable extent as in the sample of TBP-F, the blue color became weak in its intensity and the temperature region of the color development became ambiguous.

In the radiation-induced polymerization of cholesteryl acrylate in its smectic liquid crystalline state, Hardy, et al. ${ }^{4}$ have pointed out that the polymerization takes place in the crystal lattice. Although the polymerization condition and the species of monomer are not necessarily the same for those of Hardy, et al., the mechanism of color development may originate from a mesomeric order of the monomeric CMA coexisting in the polymeric system because such a color development was not observed for the purified polymer, which was precipitated from the chloroform solution of the polymer by dilution with methanol for separating the monomer, and for the polymers prepared by a thermal bulk polymerization in the isotropic liquid states. at 120 and $140^{\circ} \mathrm{C}$. Details of the temperaturedependence of the color development, however, remain equivocal at pressent.

Either poly (CMA) prepared from the thermal polymerization in the mesophase or in the isotropic liquid state was soluble in benzene, toluene, chloroform and tetrahydrofuran, and was insoluble in methanol and ether. Unlike the result reported by Toth and Tobolsky ${ }^{1}$ on the thermal polymerization of cholesteryl acrylate, the ring double bond in the cholesteryl pendant group did not participate in the polymerization. This was confirmed by the IR

Table III. Tacticities of PMMAs derived from poly (CMA)s ${ }^{\mathrm{a}}$

\begin{tabular}{cccc}
\hline \multirow{2}{*}{$\begin{array}{c}\text { Original } \\
\text { sample }\end{array}$} & \multicolumn{3}{c}{ Tacticity, \% } \\
\cline { 2 - 4 } & $S$ & $H$ & \multicolumn{1}{c}{$\boldsymbol{I}$} \\
\hline TBP-F & 81.4 & 15.4 & 3.2 \\
TBP-7 & 82.2 & 12.6 & 5.2 \\
TBP-9 & 69.4 & 20.2 & 10.4 \\
\hline
\end{tabular}

a $S, H$, and $I$ denotes syndiotactic, heterotactic, and isotactic component, respectively. 
spectra of the polymers.

In comparison the conversion of thermal polymerization in the mesophase is higher than in the case of the isotropic liquid phase polymerizations. The similar results have been reported by Amerik, et al., ${ }^{5,6}$ for the radiation-induced polymerization of vinyl oleate and for the radical polymerization of $p$-methacrylyloxybenzoic acid.

Stereospecific structure of poly(CMA) was determined by observing NMR spectra of polymethylmethacrylate $(10 \mathrm{w} / \mathrm{v} \%$ in chloroform solvent, $55^{\circ} \mathrm{C}$ ), which was derived from a hydrolysis of poly(CMA) by concentrated sulfuric $\operatorname{acid}^{7}$ and a subsequent methyl-esterification of the resultant polyacrylic acid with diazomethane. ${ }^{8}$ Tacticities thus obtained are shown in Table III. The experimental result suggests that there is no significant difference in tacticity between the original poly(CMA) obtained in the mesophase and those obtained in the isotropic liquid phase.

Acknowledgement. The authors wish to express their sincere thanks to Dr. M. Hamashima of the Government Chemical Industrial Research Institute, Tokyo for the GPC measurements and to the Hitachi Scientific Instruments Center for letting them use a DSC.

\section{REFERENCES}

1. W. J. Toth and A. V. Tobolsky, J. Polym. Sci., Part B, 8, 289 (1970).

2. A. C. de Visser, J. Feyen, K. de Groot, and A. Bantjes, ibid., Part B, 8, 805 (1970).

3. H. C. Brown, J. Amer. Chem. Soc., 60, 1325 (1938).

4. Gy. Hardy, K. Nyitrai, and F. Cser, Preprints, International Symposium on Macromolecular Chemistry, Budapest, August 1969, 4, p 121.

5. Y. B. Amerik and B. A. Krentsel, J. Polym. Sci., Part C, 16, 1383 (1967).

6. Y. B. Amerik, I. I. Konstantinov, and B. A. Krentsel, ibid., Part C, 23, 231 (1968).

7. E. M. Loebl and J. J. Nell, ibid., 45, 538 (1960).

8. A. Katchalsky and H. Eisenberg, ibid., 6, 145 (1951). 